\title{
TOWARDS A 21ST CENTURY COMPETENCY-BASED MODEL OF HIGHER EDUCATION: THE PRAGMATICS OF ACCOUNTABILITY
}

\author{
Samira Elatia ${ }^{1 \star}$, Donad Ipperciel ${ }^{2}$ \\ ${ }^{1}$ University of Alberta, Campus Saint-Jean Edmonton, Alberta Canada \\ ${ }^{2}$ Donad Ipperciel, York University, Glendon College Toronto, Ontario, Canada \\ ${ }^{*}$ Corresponding author
}

\begin{abstract}
The 21s century brought unprecedented changes to higher education where the focus is increasingly on building competencies or attributes that would allow graduates (1) a better preparation to job markets and (2) an application of their learned knowledge and skills in their roles as 'glocal' citizens. Many aspects of competency in higher education and graduate attributes (GA) have been discussed in recent years, be it at the level of conceptualization, stakeholder identification and relative weighting, implementation strategies, curriculum approaches, staff development, quality assurance or the role of students (Hughes \& Barrie, 2010). Accountability of various stakeholders is key to the success of a systematic assessment process that should be done in a continuous cyclic loop of feedback (Dugan 2004). With this loop of feedback, improving the learning outcomes and ensuring that the graduating attributes are met during the academic process and after degrees are granted. In this paper, we aim first to tackle the issue of defining competencies by delving into various works that has been done so far on defining competencies and GA. We then present some competency based models in various level of education. Finally, we identify stakeholder and discuss their roles in defining accountability parameters for a criteria-based method of assessment that would allow for comparison between the acquisition levels of different GAs at an institution-wide level.
\end{abstract}

Keywords: Graduating attributes; Competency-based model; Higher education; Formative Assessment, Accountability.

\section{INTRODUCTION}

While the question of competency in education is not new in itself, having been discussed since the 1950s in the work of Bloom and others, and even back to the 19th century in the vocational education and training, the last two decades have witnessed a major shift towards a competency-based approach to education at different levels of schooling. Government agencies and educational bodies around the world are looking into the competencies that they would outline for their educational objectives. Competency-based is an "approach which structures learning around competencies defined as fundamental for successful performance" (Stoffle \& Pryor 1980, 55).

There are two fields in which the competency-based model has made great strides. First, within adult continuing education, professional and vocational training and for work enhancement purposes: major advances have been made as these fields require concrete and easily identifiable skills. For instance, establishing competency for electricians or welders is straightforward: an electrician needs to be able to perform clearly defined tasks following specific guidelines and directives. In a professional setting with clearly 
defined standards, competencies can be easily identified, acquired and most importantly measured. Second, in elementary and secondary education: establishing competencies is fairly straightforward, as foundational knowledge and skills are being targeted. For instance, competencies such as literacy and numeracy can be measured and directly linked to curriculum and teaching/learning objectives set by national and local educational bodies. There is a continuum in learning to read that starts with recognizing letters, words, and simple sentences in grade 1 , and leads to reading a novel and synthesizing its content in grade 12 . At each step, improvements can be ascertained and assessed.

However, at the university and college levels, apart from technical and professional programs, establishing and measuring competencies is far from simple. Most universities that have elaborated competencies have adopted graduate (or graduating) attributes (GAs) based on their values and general outlook. These attributes are in line with the institution's vision and mission, but they scarcely target specific, unambiguous skills, thus making them difficult to measure. Moreover, the issue of competencies is further complicated by the various stakeholders who are accountable or hold others accountable for these competencies. Hence, competencies and GAs might be restricted to a general descriptive, perhaps aspirational role within university education. The multifariousness of students from diverse age groups, with diverse academic, personal interests and backgrounds, make the development and use of competencies in higher education a multifaceted and complex undertaking.

University education in its classical humanistic sense holds a special place in society: it is the breeding ground for knowledge and ideas in their most noble sense. Yet, the last decade in particular has seen a wave of competency models being developed by various institutions around the world, seemingly bringing university ideals back to earth. In this paper, we aim primarily to provide a solid foundation for and understanding of this new wave of the competency-based approach. In order to do this, we delve into the various definitions of competencies (from a historical as well as a conceptual perspective), focus on the axiological nature of competencies, explore the many stakeholders and accountability relationships involved in establishing competencies in the educational context and highlight the relationship that binds the two.

\section{DEFINING COMPETENCIES}

There are two intertwined connotations of the word 'competency', which refers both to output (i.e. instruction results) and input (i.e. underlying attributes that are required of an individual to perform at a certain level of satisfaction) (Hoffman, 1999). In a sense, both meanings complement each other, as one covers the acquisition process while the other describes its goal or end product.

In general terms, the Organization for Economic Cooperation and Development (OECD) defines competency in Definition and Selection of Competences report as a "the ability to meet demands or carry out a task successfully, and consists of both cognitive and non-cognitive dimensions" (OECD 2002, p. 8). Competency has always been linked to skills, abilities, capability and the like. In fact, these terms have, over time, been used interchangeably with competency. However, in educational sciences, they are used in a more specific sense, although even within the broad field of education, they may carry various meanings depending on the sub-discipline.

Haladyna proposes the following breakdown:

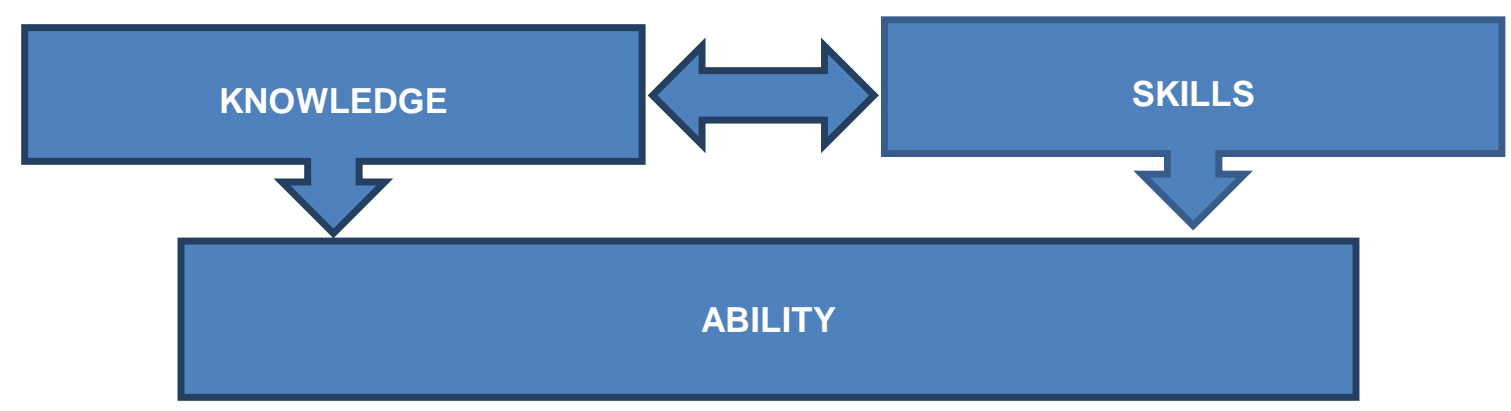

Figure 1: Relation of knowledge and skills to ability (Haladyna 1997, 7)

- Knowledge comes first and is the foundation of any learning. It is important, when dealing with competencies, to distinguish between acquiring or preserving knowledge on the one hand and actually using it on the other hand (Haladyna 1997). 
- Skills "are complex acts that require knowledge and involve performance. We have mental and physical skills, some that are easily visible and others that are less visible, but must be inferred through student behavior." (Haladyna 1997, p. 8). In short, skills are about doing on the basis of knowledge.

- Ability is more complex and involves both knowledge and skills. Ability emerges later in the learning process as more knowledge and skills are assimilated and mastered. Ability is about mobilizing knowledge and skills for a meaningful purpose.

Within Haladyna's framework, competency as it relates to a performance is closely linked, at times even synonymous with, "ability" in the KSA model for education.

While many believe skills and competencies to be identical, Ananiadou \& Claro (2009), in their eight-year seminal work for DeSeCo (Definition and Selection of Competencies) state that a "competence is more than just knowledge or skills." For instance, a person might have the skills to change light bulbs and light switches around the house, but this does not mean that $\mathrm{s} /$ he is a competent electrician. Competence "involves the ability to meet complex demands, by drawing on and mobilizing psycho-social resources (including skills and attitudes) in a particular context" (Ananiadou \& Claro, 2009, p. 8). For Ananiadou \& Claro, thus, competency involves not only knowledge and skills, but also more abstract qualities such as attitudes. They believe that the new skills and competencies are those "that young people will be required to have in order to be effective workers and responsible citizens in the knowledge society of the $21^{\text {st }}$ century" (p. 5).

The broadly social aspect of the concept of competency is apparent in the DeSeCo Project report published by the OECD's European Association for the Education of Adults in 2002, which aimed at building a better understanding of key competencies for adult education. According to this report, competence involves more than knowledge and skills; rather, it includes attitudes that contribute to successfully carrying out an activity or task (p. 6). This is a functional approach whereby defining competencies is linked to external use and application in society. This view is similar to that of the European Centre for the Development of Vocational Training, whose glossary defines a skill as the "ability to perform tasks and solve problems" (Cedefop, 2011, p. 162), while defining a competence as the "ability to use knowledge, skills and personal, social and/or methodological abilities, in work or study situations and in professional and personal development." (p. 36). In this view, competencies are situational (they make sense within a broad context of human activities) and teleological (they aim at reaching a meaningful goal by mobilizing knowledge, technical skills and social qualities). By contrast, skills related to context-free tasks that can or cannot be accomplished.

In line with this interpretation, the Province of Alberta's Ministry Education provides the following definition of competency: "an interrelated set of attitudes, skills and knowledge that is drawn upon and applied to a particular context for successful learning and living. Competencies are developed over time and through a set of related learner outcomes" (Alberta Education, 2011, p. 3). Thus defined, 'competency' is a broad term that refers to the general development of a fulfilled individual in a social as well as a professional setting. As such, it includes the following: critical thinking, creativity, social responsibility, communication, collaboration, and so on (ibid.).

Understood in this way, competencies intersect with the concept of graduate attributes (GAs), a term used typically in higher education, but which, historically, has developed independently from the concept of competency in primary and secondary education. Interestingly, both academic levels (pre-college and postsecondary) arrive at the same understanding of complex, socially relevant, situational and teleological abilities, yet following distinct paths and using a distinct vocabulary. GAs are defined most commonly as "the qualities, skills and understandings a university community agrees its students would desirably develop during their time at the institution that consequently shape the contribution they are able to make to their profession and as a citizen"(Bowden et al., 2000). Similarly to competencies, GAs include attitudinal and dispositional qualities. Typical GAs are communication skills, critical thinking, ethical responsibility, collaborative skills and ethos, creativity, and so on, traits that mirror competencies, as identified above. They are a miscellany of applied knowledge, understandings, skills, attitudes, values and dispositions (Hager \& Holland, 2006, p. 3).

It is precisely the heterogeneous nature of GAs or competencies that makes their assessment and measuring a difficult task. Although many commentators have given up on the possibility of measuring GAs (Pitman \& Broomhall 2009, p. 450), most would agree that this is critical to any implementation of a GA scheme (Hughes \& Barrie, 2010, p. 326-7; Fraser \& Thomas, 2013, p. 549). Thus, there is a need for an assessment-oriented taxonomy of GAs (a project that the authors have undertaken in a yet unpublished article; Ipperciel \& EIAtia 2014). 


\section{ESTABLISHING COMPETENCIES AND INDICATORS}

Competencies are domain-specific and depend to a large extent on the context (DeSeCo report 2005). That is, the context and environment will dictate which ones should be used and how they should be adopted and implemented. Choosing relevant competencies depends to a great extent on what is valued (DeSeCo, 2002), above all by stakeholders (more on this in the last section of this paper). This explains why there are multiple competencies that serve different purposes. Given the context-dependent nature of competencies and GAs, no one set of competencies should be regarded as authoritative and definitive in all possible settings. This, in our mind, renders irrelevant a number of articles on GAs that set out to accomplish precisely this.

Competencies, as they are understood in this context, are value-bound in a broad societal sense. It is often 'for society' or the full development of its members that several competencies have been worked out. Whether as "essential", "generic" or "key", competencies matter because they help people flourish within society. Key competencies are "influenced by what societies value and by what individuals, groups, and institutions within those societies consider important" (p. 8). Key competencies are those that are "important across multiple areas of life and that contribute to an overall successful life and a well-functioning society" ( $p$. 14). Traditionally, governments have proffered their own key competencies and, in most cases, these have included effective communication, critical thinking and problem solving, as well as ethical and respectful citizenship. Philosophers and ethicists have also attempted to define the competencies needed in general for the good of society (Canto-Sperber \& Dupuy, 2001).

Evidently, academic institutions are strongly influenced by societal values, although the prevailing axiological plurality leaves sufficient room for choice. Apart from the value-bound competencies, they also pursue their own distinctive skills-based goals, which give rise to the distinction between disciplinary and cross-curricular (or cross-cutting) competencies. The 'Programme de formation de l'école québécoise" of the Quebec Ministry of Education identifies these two overarching competencies as being central in education. The disciplinary competencies are linked specifically to a program of study. Competencies developed within this framework establish a continuum in mastering the content of the target discipline. The "compétences transversales' (cross-cutting competencies) as they are referred to in Quebec are much broader and focus on the holistic learning of students as preparation for society. These competencies constitute a behavioral know-how [savoir-agir] based on the mobilization and efficient use of a range of resources. However, they offer a wider frame of reference insofar as they cross disciplinary boundaries and enable a wider range of action. They often have the merit of mobilizing resources from more than one discipline for the benefit of a same objective. [Our translation] (MELS, 2008)

The graph below is a representation of both types of competencies for secondary education in the province of Alberta, by the ministry of education Alberta Education.

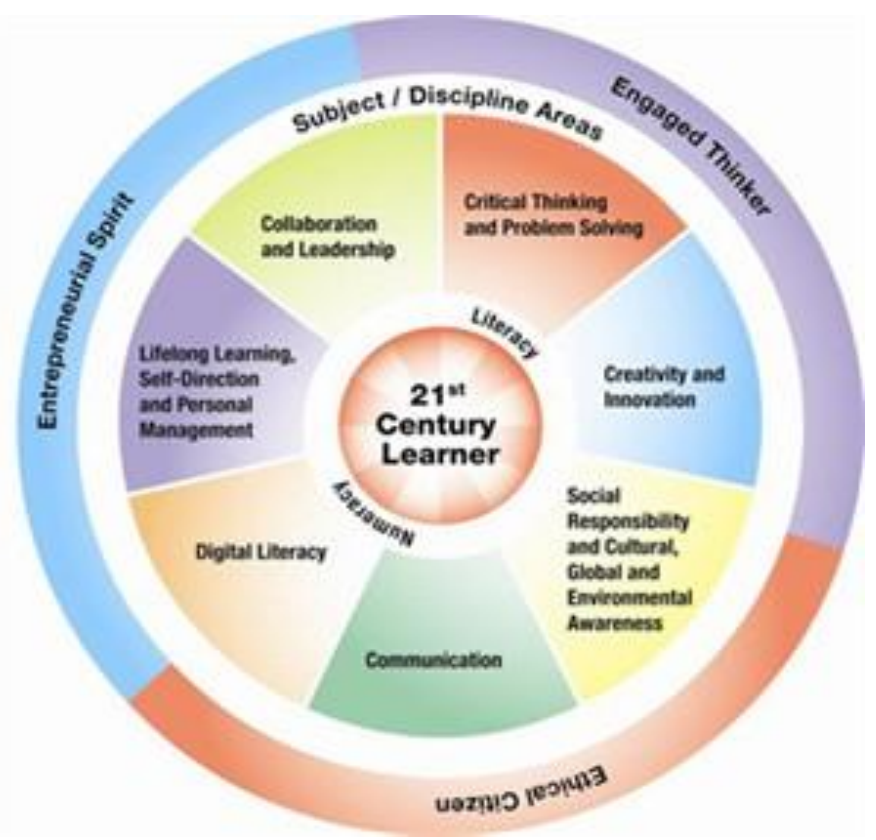

Figure 2: Alberta Education Framework for Student Learning (Alberta Education 2011, 2) 
In elementary and secondary education, bodies governing the education system - whether federal, provincial or state level ministries, depending on countries - are in charge of developing competencies. In most cases, these agencies are also responsible for curriculum development. In higher education, by contrast, it is often up to institutions themselves to develop their own competencies, which in liberal arts programs and institutions take on the form of cross-cutting competencies. Students, in this context, apply the acquired knowledge in a holistic way that transcends the classroom and prepares them for society and life beyond the academic setting. Professional programs (e.g. engineering, nursing, etc.), though they also must adopt disciplinary standards, nonetheless integrate, in many cases, broader cross-cutting graduate attributes.

Australia and the United Kingdom are certainly forerunners with regard to implementing graduate attributes at the higher education level. In the United States, efforts have been rather timid, with the notable exception of Alverno College. In Canada, the University of Alberta is among the few institutions that have fully adopted this model with the support of a student-driven initiative that has seen to the creation of a committee whose objective was to identify core competencies known as GAs. This committee's work follows from the University of Alberta's current academic plan entitled "Dare to Deliver" which promises to "foster and enhance learning, discovery and citizenship" by developing "attributes and competencies upon graduation", that is, by "[a]rticulating and supporting the development of core sets of skills, attributes and values to be incorporated into graduate and undergraduate programs" (University of Alberta, 2011, p. 13). The committee's work identified the following seven competencies as GAs applicable to the university undergraduate and graduate students: ethical responsibility, scholarship, critical thinking, communication, collaboration, creativity, confidence.

Once general GAs or competencies are elaborated, the issue that arises is about defining the attributes that describe a specific competence or GA and hence facilitates implementation and use. In all cases, agencies that develop competencies have to supplement the generic competencies with detailed descriptions that provide more pragmatic explanation to what they mean, so that stakeholders can understand what is being targeted, and to how to potentially assess these competencies.

For the two GAs 'Communication' and 'Collaboration,' the following sub-attributes were identified:

Communication: writing skills, oral skills, visual communication, multilingualism

Collaboration: openness to diversity, interpersonal skills, adaptability and compromise, individual contribution.

The subsequent step consisted in having individual faculties develop their own interpretation (in the form of can-do statements) of these sub-attributes following their own culture and values, as well as the needs and realities of their programs.

\section{STAKEHOLDERS AND ACCOUNTABILITY}

In order to deepen our understanding of the concept of competency, a number of pragmatic, context-related questions should be raised, which will set the stage for a non-abstract understanding of the concept and, ultimately, for building valid assessment models.

In classical higher education, i.e. universities and institutions that are not professional and vocational schools, the following questions should be addressed:

- Who identifies the competencies? Who is involved in the process?

- Who are the stakeholders? What are their roles? And what is the purpose and goals of taking part in this process?

- Who is accountable? Who does the monitoring? Who provides feedback? Who benefits (or not) from a GAs and competencies framework?

The use, implementation and interpretation of competencies depend to a great extent on the stakeholders involved in this process. Stakeholders are in fact, from a pragmatic point of view, the driving force behind the use of competencies. Undoubtedly, they are central to the whole process. The list of stakeholders is potentially long and may include: university administrators, potential employers, students at various levels, teachers at various ranks and with various responsibilities, funding agencies and government offices (see Chart 2 below). The list could be further extended, but let us focus on those stakeholders who have a direct impact on the competency-based model of higher education. 


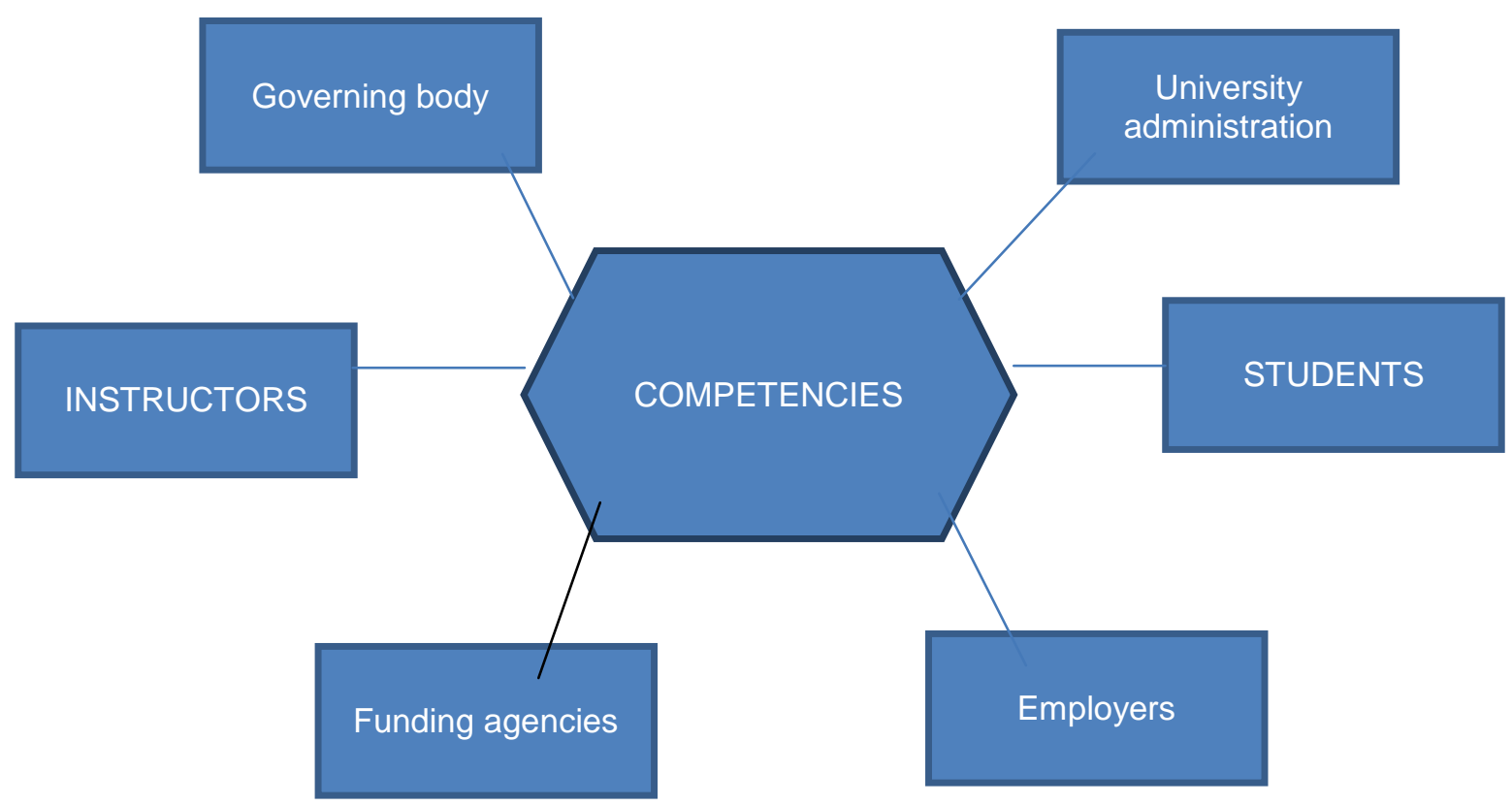

Figure 3: University Stakeholders Relations to Competencies

In a previous study (Ipperciel \& EIAtia, 2014), we identify the relationship between student and instructor as a core element of the assessment process. This relationship provides a continuum in which one can gain insight into the workings of competencies for learning and teaching. This relationship is essential to the formative and diagnostic evaluation of competencies.

That being said, university administrators also have a strong vested interest in competencies or graduate attributes. Higher education competencies differ from those in secondary and elementary, as well as professional institutions, in that a university's mission and vision statement feed directly into the adoption of the competencies that are deemed essential. In most cases, it is university administrators that initiate the work of setting up competencies, although student input is often sought for legitimacy purposes (as in the University of Alberta example, above). Anderson (2004) argues that among the responsibilities of academic and administrative university leaders is the collection of information on student performance indicators in order to "facilitate the development of conceptual frameworks and paradigms that are both discipline specific and that cut across academic areas." (p. 19)

Funding agencies and government offices also have stakes in competency-based approaches because they are responsible for setting standards, ensuring quality control and advancing social and economic agendas, with a view to enhancing well-being through social and professional development. The strong involvement of governments across the world (Australia, European Union, Alberta, Quebec, etc.) in promoting competencybased approaches (including graduate attributes) comes as no surprise.

Employers are another important stakeholder. While they may not be involved in the implementation process, they are most interested in the graduating attributes of students as potential employees. This is why graduate attributes are often understood in their relationship to employability (Hager \& Holland, 2006). Australian universities often produce GA toolkits that draw on employers point of views (e.g. Griffith University, 2011) and special attention is given to employer satisfaction with graduates key capabilities (e.g. Walker, 2008).

All these stakeholders have a role to play in the various stages of developing and implementing any competency-based model. They are in a position to enrich it by adding various perspectives. Stakeholders are also accountable for input and outcomes related to using competencies. They require accountability from each other in order to ensure that GAs and competencies do in effect provide an educational added value based on criteria of success and completion; and not based solely on normative standardization. For accountability then, there is a need for a full-fledged assessment model. Dugan (2004) advocates for a systematic assessment process that should be done in a continuous cyclic loop of feedback as key to the success of competencies implementation. This loop of feedback from all identified stakeholders plays a 
pivotal role in improving the learning outcomes and ensuring that the graduating attributes are met during the learning process and after degrees are granted. For Baker (2002), the quality of institutional outcomes depends on the quality of quantifiable institutional inputs.

What made competency-based education 'successful' in elementary and secondary education, is the demonstration of learned/acquired competency (Stoffle \& Pryor 1980), based on various tests that are implemented throughout the academic years. Effectiveness of programs of study and accountability of stakeholders is fundamental to the drafting of assessment models that would work at higher education. Direct testing and measurement may not be the solution because it targets specific constructs that are not necessarily aimed at in a set of competencies identified by university.

\section{CONCLUSION}

Implementing competency-based education has been successful when the criteria to be assessed are clear, straightforward and directly tested. Both in professional and vocational programs, as well as in elementary and secondary education, competencies are concrete and follow a predictable progress. In the traditional university education, however, it is challenging to identify such competencies and, moreover, it is extremely difficult to test.

Within a formative model of assessment in which the stakeholders are accountable for their roles and are part of this assessment process, competencies could be assessed via longitudinal survey tools that track the progress of the students' acquisition of these competencies and evaluate the courses suitability to addressing them.

\section{REFERENCE LIST}

Alberta Education (2011). Framework for student learning: competencies for engaged thinkers and ethical citizens with an entrepreneurial spirit. Alberta Education, Edmonton. Online: http://globeclassroom.ca/userfiles/Alberta_Framework.pdf.

Ananiadou, K., \& Claro, M. (2009). 21st century skills and competences for New Millennium Learners in OECD countries. Paris, France: Centre for Educational Research and Innovation (CERI)- New Millennium Learners.

Anderson, J.(2004). An institutional commitment to assessment and accountability. In Hernon. P \& Dugan.R (eds). Outcomes Assessment in Higher Education: Views and Perspectives. Westport, CT: Libraries Unlimited

Baker, R. L. (2002). Evaluating Quality and Effectiveness: Regional Accreditation Principles and Practices. The Journal of Academic Librarianship, 28, 3-7.

Bowden, J., Hart, G., King, B., Trigwell, K., \& Watts, O. (2000). Generic capabilities of ATN university graduates. Canberra: Australian Government Department of Education, Training and Youth Affairs.

Canto-Sperber, M. \& Dupuy, J.P. (2001). Competencies for the good life and the good society in D. S. Rychen \& L.H. Salganik (eds.). Defining and selecting key competencies. Seattle: Hogreffe \& Huber, pp. 67-92.

Cedefop (European Centre for the Development of Vocational Training) (2011). Glossary/ Glossar/ Glossaire. Luxembourg: Publications Office of the European Union.

Dugan, R (2004) Institutional Assessment Planning in Outcomes Assessment in Higher Education (Hernon, P. \& Dugan, R eds.) Westport, Connecticut: Libraries Unlimited.

Fraser, K. \& Thomas, T. (2013). Challenges of assuring the development of graduate attributes in a Bachelor of Arts. Higher Education Research \& Development, 32 (4), 545-560.

Griffith University (2011). Griffith Graduate Attributes Teamwork Skills Toolkit. Gold Coast, Grifitth University. On line: http://www.griffith.edu.au/_data/assets/pdf_file/0008/290870/Teamwork-skills.pdf. 
Hager, P. \& Holland, S. (Eds.). (2006). Graduate Attributes, Learning and Employability. Dordrecht: Springer.

Haladyna, T. (1997). Writing Test Items to Evaluate Higher Order Thinking. Needham Heights, MA: Allyn and Bacon.

Hoffman, T (1999). The meaning of competency. Journal of European Industrial Training, 23 (6)0, 275-286.

Hughes, C. \& Barrie, S. (2010, May). Influences on the assessment of graduate attributes in higher education. Assessment \& Evaluation in Higher Education, 35(3), 325-334.

Ipperciel, D. \& ElAtia, S. (2014). Assessing Graduate Attributes: Building a Criteria-Based Competency Model. The International Journal of Higher Education, 3 (4), 27-39.

MELS [Ministère de l'Éducation, du Loisir et du Sport] (2008). Programme de formation de l'école québécoise. Compétences Transversales. Online: http://www1.mels.gouv.qc.ca/sections/programmeFormation/secondaire2/medias/3-pfeq_chap3.pdf

Organization for Economic Co-operation and Development (2002). Definition and selection of competencies (DeSeCo): Theoretical and Conceptual Foundations. On line: http://www.oecd.org/education/skillsbeyond-school/41529556.pdf

Organization for Economic Co-operation and Development (2005). The Definition and selection of key competencies: Executive Summary. On line : http://www.oecd.org/pisa/35070367.pdf

Stoffle, Carla J. \& Judith M. Pryor. (1980). Competency-Based Education and Library Instruction. Library Trends, 29(1), 55-67

University of Alberta (2011). Dare to Deliver. Academic Plan 2011-2015. On line: http://www.provost.ualberta.ca/en/ /media/provost/Documents/Academic\%20Plan/AcademicPlan2015 .pdf.

Walker, Narelle (2008). Teaching Quality Indicators Project. Adelaide, University of South Australia. Online: http://www.uwa.edu.au/_data/assets/pdf_file/0005/1891454/UniSA_Final_Report.pdf. 